\title{
Wohlfart Kugelberg Welander Syndrome
}

\author{
R. T. ROSS, CHARLES A. SIMPSON, AND SALMA STYLES
}

SUMMARY: A family is described with two brothers suffering from the Wohlfart Kugelberg Welander syndrome, and seven unaffected siblings. Another brother died in infancy from "a spinal disorder'. Both affected males developed symptoms in the third decade with weakness of the lower limb girdle, followed by the upper limb girdle. Both showed fasciculations, hyporeflexia, and purely lower motor neuron findings. EMG showed evidence of denervation and muscle biopsy showed neurogenic atrophy. Terminal motor latencies were slightly prolonged and one showed an elevated serum aldolase while both had elevated C.P.K.'s. Laboratory studies on

RÉSUME: Dans une famille, deux frères souffrent du syndrome de Wohlfart Kugelberg Welander, tandis que les sept autres frères et soeurs sont normaux. Un autre frère est mort dans son enfance de "désordre de la moelle épinière". Chez les deux hommes atteints, les symptomes se sont développés au cours de la troisième décade, par une faiblesse de la gaine du membre inférieur, suivie de la gaine du membre supérieur. Tous deux manifestaient des signes de fasciculations et d'hyporéfléxie ainsi que des troubles clairs du neurone moteur inférieur. L'EMG mit en évidence la présence d'une dénervation, et la biopsie du muscle révéla une atrophie neurogénétique. Les latences motrices finales étaient légèrement prolongèes, et l'un d'eux montra un taux élevé de sérum aldolose, alors que tous deux avaient des C.P.K. élevés. Les études some of the normal siblings were normal. The younger brother who has been seen over two years seems to have become slightly stronger.

Dermatoglyphics and chromosomal analysis have been carried out on the patients and some of the normal siblings. All were normal except for the younger affected brother who has persistently showed a high percentage of abnormal cells, though the basic karyotype was normal, and abnormal dermatoglyphics.

This is the only case we have found in the literature with chromosome abnormalities. This pedigree suggests a recessive inheritance, possibly $x$ linked.

de laboratoire faites sur quelques uns des autres frères et soeurs furent normales; le plus jeune des frères, qui a été observé pendant plus de deux ans, semble être devenu légèrement plus fort.

Des dermatoglyphies et des analyses chromosomiques ont été pratiquées sur des patients et sur quelques uns des frères et soeurs normaux; tous les résultats furent normaux, sauf pour le plus jeune frère atteint chez qui on décela continuellement un fort pourcentage de cellules anormales, alors que le karyotype de base était normal, et les dermatoglyphies anormales.

Il s'agit du seul cas avec des anomalies chromosomiques que nous ayons trouvé dans nos archives. Cette généalogie suggère une descendance récessive probablement liée à $x$.

From the Section of Neurology, Winnipeg General Hospital and the University of Manitoba, Winnipeg, Manitoba, (R.T.R.); and the Departments of Neurology (C.A.S.) and Pathology, (S.S.) The Royal Jubilee Hospital, Victoria, British Columbia.

Reprint address - Dr. R. T. Ross 132-404 Graham Avenue, Winnipeg R3C 0L6 Canada.
Juvenile and adult chronic spinal muscular atrophy (SMA) is initially a disease of proximal muscle wasting due to a lesion of the anterior horn cell. It is characterized by a lengthy course and is heritable. It is distinct from amyotrophic lateral sclerosis, both sporadic and familial, and may be part of the spectrum of infantile spinal muscular atrophy (WerdnigHoffmann Disease).

Wohlfart (1942) identified the disease. He observed patients with apparently conventional, limb girdle, muscular "dystrophy" in whom fasciculation was present. He summarized the literature on these patients and added two new ones of his own. Muscle biopsies in his cases showed changes which were interpreted as a combination of dystrophic and neurogenic disease.

Kugelberg and Welander (1952) re-examined one of Wohlfart's original patients electromyographically, and thought the disease was neurogenic. They collected several similar patients and concluded that the disease was a separate, hereditary, wasting disorder. Subsequently, Welander (1955) reported on a post-mortem examination of one of these patients, and stated that the pathology was localized to the spinal anterior horn cells.

This was followed by a report of Wohlfart, Fex, and Eliasson (1955) describing three families containing seven patients with various manifestations of the syndrome. The most similar patients were males, with the onset between fourteen and seventeen years and slowly progressive weakness and wasting of proximal limb muscles and eventually trunk muscles. The sternomastoids and facial muscles were normal. All showed fasciculations and diminished or absent tendon reflexes, the 
exception being a normal ankle reflex. All had electromyographic evidence of denervation and a biopsy done on one patient revealed neurogenic atrophy. Bulbar involvement and upper motor neuron signs were not part of the syndrome.

Their other patients were less stereotyped. Patients number three and five might reasonably be diagnosed as Werdnig-Hoffmann's disease, while patient four with onset prior to age ten was undiagnosed. Patient number six, though undiagnosed, had the appearance of benign congenital hypotonia.

The syndrome gained wider recognition with the publication of Kugelberg and Welander (1956). They reported twelve patients belonging to eight sibships in six pedigrees. There was no direct transmission from parent to child, and as more than one member was affected in most of the pedigrees, the disease was apparently hereditary and thought to be recessive. Their patients varied in age from twelve to fifty-seven, and the duration of symptoms varied from nine to forty years. Eight were males. The age at onset varied from two to seventeen years with an average of nine. Early development was normal and the first symptom was proximal leg weakness, followed by proximal arm weakness after several years. Facial muscles, sterno-mastoids, sphincter control and sensation were normal. They showed neither bulbar or upper motor neuron signs. Fasciculation was common. Reflexes were diminished or absent, the ankle jerk being the best preserved. Intelligence was unimpaired, and there was no evidence of cataract. Electromyography performed on nine patients was typical of chronic lower motor neuron disease. Biopsies from five subjects, belonging to different pedigrees, showed the changes of spinal atrophy. The disease was slowly progressive. Two patients lost the ability to walk eight years after the onset while seven could still walk twenty years after onset, and one, forty years after onset. The rate of progression was independent of sex and the age of onset.
Since these four papers there have been several dozen reports with increasing variations in the classical syndrome. Magee and Dejong (1960) reported three members of one family with slowly progressive proximal limb weakness and wasting. A seven year old boy had been affected since age three, his five year old sister had developed weakness at eighteen months. Their forty year old mother had developed proximal leg and arm weakness at about age three years and her disease was static. All three maintained their tendon reflexes and their biopsy specimens suggested a neurogenic atrophy.

Smith and Patel (1965) reviewed the literature and reported forty-eight patients in detail. They added a case of their own. Armstrong et al (1965), (1966) studied a large negro pedigree extending over three generations. In this family the disease began between ages one and ten. Several of these patients had no fasciculation and many were not disabled up to the third and fourth decade. Engel (1965) reported six families studied by Hogenhuis and himself. Most of the patients were males. They all showed a moderately elevated serum creatine phosphokinase. Gross (1966) described three adult male examples of the disease. None had a family history.

Garvie and Woolf (1966) described six patients in two unrelated families. Two of their patients first showed the disease in infancy while a third was well until age fourteen. Enzymes were normal. Electrical studies and biopsies suggested a neurogenic disease.

Gardner-Medwin et al (1967) presented a detailed study of seventeen patients of which more than half were isolated cases. Smith and Patel (1965) had found that thirty percent of their forty-eight cases had no family history. Eight were female. The age of onset varied, the majority starting in the first two years of life. Unlike most reported series, three of their patients died, two, five, and twelve years after the onset of the disease. In the remaining patients, the disease ran a variable course, although it generally worsened. Often there were long static periods, and sometimes periods of definite improvement.

Almog and Tal (1968) described a family with Kugelberg-Welander disease. They reported normal serum enzymes, but four of their patients had increased amino acid uria. Spira (1966) performed electromyographic and histologic studies on the same family. Both methods confirmed the neurogenic basis.

McLeod and Williams (1971) presented twelve cases of chronic spinal muscular atrophy, both the Werdnig-Hoffmann and KugelbergWelander type. None of their patients had facial or bulbar involvement and none of them had long tract signs or fasciculation. In their group, only one example of the juvenile type had an affected sibling. Meadows et al (1969) reported on chronic spinal muscular atrophy in adults. They point out that some patients started their disease in adult life and others have had bulbar and/or pyramidal tract involvement. They also found the serum enzymes raised in some instances. Nine of their patients were male and seven were females. Seven of their patients had bulbar signs.

Tsukagoshi (1965) was the first to record bulbar signs in proximal spinal muscular atrophy. In another report by the same author (Tsukagoshi, 1970) all of the patients were tremulous and had fasciculation of the face. Some of them had elevated CPK, dysarthria, dysphagia and cramps. Like one of the patients in this presentation, some of them had gynecomastia. Fenichel (1967) described a mother and daughter with proximal limb weakness plus facial muscle involvement.

Quarford et al. (1970) investigated a family with type II hyperbetalipoproteinemia. The four older affected male members had chronic proximal limb weakness and wasting of neuropathic origin. Fasciculation of face, tongue, trunk and limbs was prominent as was muscle cramping on exertion.

Pearce and Harriman (1966) described two cases of chronic spinal muscular atrophy with pyramidal tract signs. Four patients of 
Gardner-Medwin et al. (1967) had extensor plantar responses. Two and probably three of the patients described by Meadows et al (1969) had extensor plantar responses, but as in other reports, the upper motor neuron signs were not prominent. In Meadows' patients (1969) the disease extended over thirty years in five patients, and in one patient, over sixty years.

Amick, Smith, and Johnson (1966) report the occurrence of the Kugelberg-Welander syndrome and the Werdnig-Hoffmann variant of progressive spinal muscular atrophy in one pedigree. Identical twin males, age thirty, developed weakness of proximal leg muscles at about age three. By fourteen, they were both in wheel chairs and proximal weakness of the arms appeared. Their niece developed weakness of proximal muscles and could not creep or stand at age twenty-two months. Three of her uncles had died between the ages of two and four years with similar histories. All three patients showed E.M.G. and histological evidence of denervation. The families of Gardner-Medwin et al (1967) show the same spectrum.

Buchthal and Olson (1970) have studied thirty patients with infantile spinal muscular atrophy. Their study included electromyography and histology. They emphasize the differences between the WerdnigHoffmann and the WohlfartKugelberg-Welander syndrome. Obviously the age of onset is different, the severity and rapidity of the disease are also different. There are substantial differences in electromyographic findings. Skeletal muscle fasciculations were not seen in any of their patients and were found electromyographically in only two.

Meadows et al (1969) found elevated serum glutamic oxalacetic transaminase (S.G.O.T.), creatine phosphokinase (C.P.K.), and serum aldolase in some patients. The C.P.K. was elevated in nine of thirteen cases in which it was estimated, as was the aldolase in three of five cases in which it was estimated. S.G.O.T. levels were less frequently abnormal. This has been described in other examples of the KugelbergWelander syndrome (Tsukagoshi, 1965 and 1966; Gota, 1967). GardnerMedwin et al. (1967) found the C.P.K. increased six times over normal in one patient and three patients had elevated serum aldolase. Spira (1966) and Almog and Tal (1968) in describing the same family report normal C.P.K. and serum aldolase as well as normal S.G.O.T. Garvie and Woolf (1966) report normal serum enzymes in one of their families. Engel (1965) reported moderately elevated C.P.K in four of the five patients examined by Hogenhuis and himself. In the family reported by Zellweger et al (1972) there were 21 affected members, males and females. Seven of nine patients studied had slightly elevated C.P.K. and aldolase was slightly elevated in four out of eight.

On the other hand, Panitch and Franklin (1972) hve reported four examples of unequivocal acute, sporadic, amyotrophic lateral sclerosis all with markedly elevated C.P.K. levels. Welch and Goldberg (1972) reported the same finding in eleven patients with this disease.

Roth et al (1965) have studied muscle fine structure in the KugelbergWelander syndrome. They examined material from five patients.

In all cases the muscle fiber was diagnostic of neurogenic atrophy. They found the over all structure of the fiber was preserved until late in the disease. Myofilaments became disorganized and broken and were found within the interfibrillar space and in areas of sarcoplasm devoid of ordered filaments. The $Z$ lines were less dense and the sarcoplasmic reticulum was represented by randomly placed tubules and vacuoles. Reduplication of the outer membrane of the sarcolemmal complex was seen. The mitochondria were normal and there were no ultrastructural changes in the nucleus.

Mastaglia and Walton (1971) have commented on the histological and chemical changes in skeletal muscles from cases of chronic juvenile and early adult spinal muscular atrophy. They review the traditional histolog- ical criteria of primary myopathic disorders. These include muscle fiber necrosis and regeneration, excess variation in size of muscle fibers, increased number of internal sarcolemmal nuclei, fiber splitting and other changes in the muscle fiber. However, they emphasize that these changes are not specific and identical changes in the more slowly progressive forms of muscular dystrophy may be found in cases of long standing neurogenic atrophy. Wohlfart's original biopsy material (1942) was interpreted as being a combination of neurogenic and myopathic disease. They suggest a possible explanation for the development of myopathic changes and for the transformation of the histochemical profile in surviving muscles in these neurogenic lesions.

Engel (1965) reported the biopsy findings in his patients. In addition to the evidence of denervation, signs of myopathy were present. Some fibers were undergoing acute necrosis and phagocytosis in an area not affected by denervation. Such a combination of myopathy and denervation atrophy has been described in another chronic motor neuropathy, i.e. peroneal muscular atrophy. It is apparent that some myopathic changes may be expected in any chronic denervation atrophy.

Kugelberg and Welander (1956) thought the condition they described was inherited in a non sex-linked, recessive manner and this has generally been accepted. Spira (1966) commented on the apparent massive gene penetrance in that four out of five, and three out of five siblings were affected in the two families he described. This is further atypical in that the parents in both these families were first cousins.

Armstrong et al (1965), (1966) reported a large family in which the inheritance seemed to be an autosomal dominant. Similarly, Zellweger (1972) reported a large kinship with 21 affected members both male and female. The inheritance appeared to be autosomal dominant.

In the family of Magee and Dejong (1960) inheritance was a simple dominant. Similarly the case described 
by Garvie and Woolf appears to be a simple dominant, at least in their second family. McLeod and Williams (1971) are of the opinion that both Werdnig-Hoffmann and WohlfartKugelberg-Welander disease may appear either as a sporadic disease or with an autosomal recessive mode of inheritance. An autosomal dominant inheritance has been described.

\section{AMYOTROPHIC LATERAL SCLEROSIS}

The occasional patient with sporadic amyotrophic lateral sclerosis may have such a lengthy course that a consideration of this disease, vis-a-vis Wohlfart-KugelbergWelander syndrome, is appropriate. Amyotrophic lateral sclerosis is usually sporadic and non-familial, but there are many case reports of the familial form. Perhaps one of the best known examples is the Farr family of Vermont, originally reported by Osler. An affected member of this family has come to autopsy and been reported by Powers et al (1974). Although the disease appeared clinically to be acute amyotrophic lateral sclerosis, the post mortem findings were consistent with the type of spinocerebellar degeneration described by Woods et al (1972).

Kurland (1957) has reported a well known study on the epidemiological investigation of amyotrophic lateral sclerosis. The incidence of the disease in the Chamorro population of the Marianas Islands is about four hundred and twenty cases per hundred thousand population. The incidence in North America and Great Britain is about four to six patients per hundred thousand population. The frequency is the same amongst the Chamorros whether they live in Guam or California (Torres, 1957). Evidently the migration of a Chamorroan from Guam to California does not prevent the disease in people predisposed to it.

Kurland and Mulder (1955) (1957) have further observations on the epidemiology of the disease in the western world. They have studied the familial incidence and reviewed in detail the pedigrees found in the literature. They found about eighteen pedigrees in the preceding one hundred years. Many of these covered three or more generations and the pattern seemed compatible with dominant inheritance. They added a further six pedigrees with thirty-four affected individuals from recent Mayo Clinic examinations. The family aggregations in all the pedigrees were compatible with a dominant form of inheritance, although there was an occasional individual who had apparently inherited and transmitted the gene while remaining free of the disease. Age of onset, duration of the disease, and selectivity by sex and nationality were discussed.

Espinosa et al (1962) also reported on hereditary amyotrophic lateral sclerosis. They emphasized that hereditary amyotrophic lateral sclerosis as seen in North America and Western Europe appeared stereotyped and different from family to family although consistent in its mode of onset and presentation within one family. They also conclude that the inheritance appears to be dominant. Similarly Green (1960) described familial amyotrophic lateral sclerosis, including seven patients in four generations. Like Espinosa (1962), he commented that the pattern of the disease was strikingly similar in siblings of the same sex. The clinical form of the disease appears to be linked with sex and age of onset.

The report of Gardner and Feldmahn (1966) consists of eighteen patients extending over one hundred and fifty-four years of family history. The inheritance in this family was dominant with incomplete penetrance. There was a low incidence in that the gene passed through three adults who themselves did not develop the disease. The average survival was fourteen months. Pathologically, they could not separate the findings in a sporadic case of amyotrophic lateral sclerosis from the hereditary form. A similar report by Roe (1964) revealed two families with amyotrophic lateral sclerosis. The onset was in the fourth and fifth decade, the course was short, and all affected members were female. Garg and Srivastava (1968) reported a girl of eight and her brother, age four. Both developed bulbar palsy and limb weakness and wasting as well as fasciculation and pyramidal tract signs. The age at onset and course of the disease seemed similar in the two. On the other hand Kennedy et al (1968) presented a study of progressive proximal, spinal, and bulbar atrophy. The disease was inherited as a sex linked recessive and became manifest in the fourth and fifth decade. Hirano et al (1967) have also reported on familial amyotrophic lateral sclerosis. Clinically, the examples were indistinguishable from random amyotrophic lateral sclerosis. Some of the findings at posi-mortem were similar to those previously described in other familial diseases, such as spinocerebellar degeneration. These consisted of involvement of both upper and lower motor neurons, of Clark's column, and a pattern of demyelination of the mid root zone of the spinocerebellar tract in the posterior columns. In addition they found intracytoplasmic accumulation of hyalin material in the affected nerve cells in the cord and medulla. A central core-like structure of hyalinized particles resembled Lewy's bodies.

Takahashi et al (1972) reported one autopsied case of hereditary amyotrophic lateral sclerosis. The cord showed degeneration in the median portion of the fasciculus gracilis and slight degeneration of the pyramidal tracts. Anterior horn cell degeneration was marked with inclusion bodies in the remaining cells. The inheritance was of autosomal dominance.

The family reported by Farmer and Allen (1969) suffered from hereditary, proximal, amyotrophic lateral sclerosis.

Ten people in the family were affected, three males and seven females, with the onset between thirty-five and fifty years of age. It started with proximal shoulder-girdle weakness and was followed by weakness of neck muscles and bulbar muscles, and eventually arms and legs. Fasciculation was common. Spasticity did not develop and death 
was due to respiratory failure. The disease was transmitted as an autosomal dominant, each affected person having an affected parent.

The family presented by Metcalf and Hiarno (1971) is distinctive. The syndrome is similar to amyotrophic lateral sclerosis, but there was the additional feature of sensory loss and a very prolonged course. Five patients were involved, and the average course lasted more than eleven years. Autopsy findings consisted of demyelination and gliosis in the spinocerebellar tract and in Goll's tract of the posterior column. In addition, there were similar changes and a loss of cells in the anterior horns. Transmission seemed to be an autosomal dominant with complete penetrance. Posser (1965) has reported on familial amyotrophic lateral sclerosis, as have Fleck and Zurrow (1967). Perry and Natsky (1958) have done the same. Pratt (1962) discussed the genetic aspects of amyogrees he examined, the inheritance was usually dominant. Sercl and Kavorik (1963) have reported a large series of familial amyotrophic lateral sclerosis. They studied a series of ninety-seven patients seen over a sixteen year period. Thomson (1969) has studied a specific type of familial amyotrophic lateral sclerosis. Excluding the Guamanian variety, he in the literature up to 1969. This particular variety begins with progressive bulbar palsy and subsequent atrophy of the muscles of the limbs. In any given family, this presentation is consistent and none of the patients trophic lateral sclerosis. In the pedifound thirty-three similar pedigrees

present upper motor neuron signs. The age of onset is also consistent between the third and fourth decade and the survival time is approximately three years.

\section{CASE REPORTS:}

Fig. 1. represents the family tree with two members affected by chronic spinal muscular atrophy. The details of the members are as follows.

Mr. D. S. No. I-A - Y.O.B. 1907. Polish born, paper maker.

No complaints and has no signs of neuromuscular disease.

Died 1972 - coronary heart disease.

Mrs. M. S. No. I - B - Y.O.B. 1904. Saulteau Indian.

Complains of tiredness and generalized fatigue. Has a past history of medically treated pulmonary tuberculosis. No signs of neuromuscular disease.

Mr. P. S. No. II - A - Y.O.B. 1929.

He has never had symptoms of muscle weakness or dysphagia. He suffered from migraine between 1961 and 1963 , but has had no attacks since that time. He had rheumatic fever thirty years ago and some sciatica with backache in 1966.

Clinical examination revealed an entirely normal, part Indian male.

Laboratory investigations were as follows: S.G.O.T., S.G.P.T., and L.D.H., all normal. Electromyography of the right quadriceps, deltoid and paraspinal muscles was normal.

Chromosome analysis of 15 cells revealed a normal male karyotype (46 XY). Dermatoglyphic analysis gave a general impression of normal dermatoglyphics. All ten digital patterns are whorls (observed in 2 to $3 \%$ of a control male population).

Mrs. N. A. No. II - B - Y.O.B. 1931.

Examination, courtesy of Dr. Peter

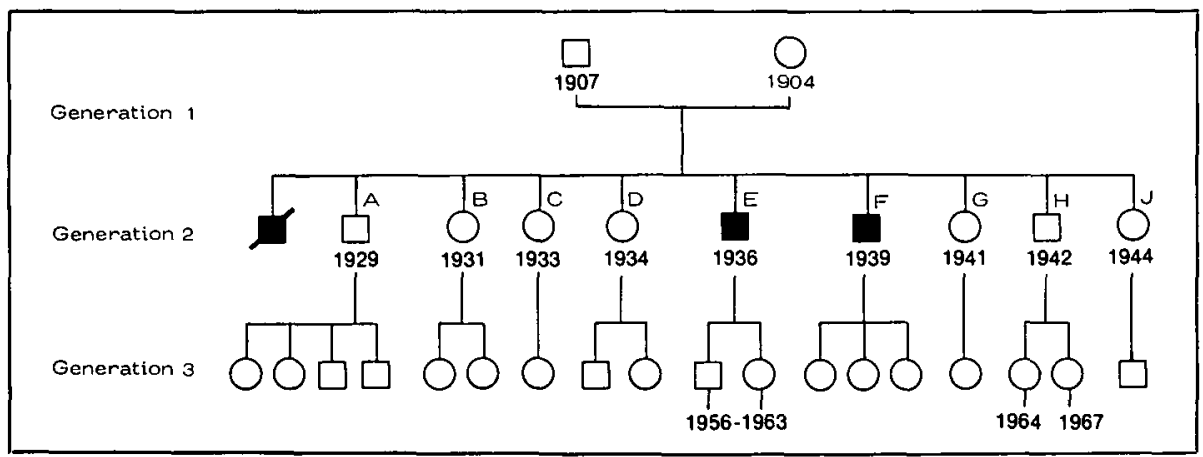

Figure I - Family tree of S family. II-E and II-F have chronic spinal muscular atrophy. First born child in this generation died at age 1 year of a "spinal disorder". $O=$ female, $\square=$ male, $\square=$ diseased, $\boldsymbol{T}=$ dead.
Siemens, Saskatoon, revealed no complaints and no abnormalities.

Mrs. E. H. No. II - C - Y.O.B. 1933

This lady was interviewed and examined courtesy of Dr. J. David Grimes, Ottawa. She had no complaints and no signs of neuromuscular disease. Normal serum enzymes included C.P.K., S.G.O.T., and L.D.H.

Mrs. F. M. No. II - D - Y.O.B. 1934.

No complaints and no abnormal signs. Normal serum enzymes included S.G.O.T., L.D.H., and C.P.K. Chromosome analysis revealed a normal female karyotype $(46 \mathrm{XX})$ with no apparent abnormalities.

Mr. R. S. No. I - E - Y.O.B. 1936.

In 1960 he began to complain of severe and persisting leg muscle cramps following strenuous exercise. At the same time his legs became weak and he experienced difficulty climbing more than ten steps. He had played professional hockey until 1955 and in retrospect thought he had given this up because of leg weakness and a general decrease in strength. In 1968 he experienced weakness in shoulders and upper arms and some trouble in lifting things above his head.

Past illnesses revealed jaundice at age thirteen, sixteen and twenty, and bilateral mastectomy in the early 1950 's.

$\mathrm{He}$ has a fifteen year old daughter and an eight year old son, both well.

On examination facial muscles were strong, except risorius: fasciculation of orbicularis oris and tongue were present. Tongue was strong and projected in the mid line. Weakness and wasting of both triceps, deltoids, and upper trapezii was seen. Pectoralis and biceps were weak, hands and forearms were normal. Abdomen and back were strong, although his posture showed an exaggerated lumbar lordosis. Iliopsoas, quadriceps, gluteii and hamstrings were moderately weak. There was slight weakness below the knee, as he could only stand on heels and toes with difficulty. The right arm had no tendon reflexes, the left, biceps only. The right knee reflex was present on reinforcement only, the left was normal. Both plantar reflexes were flexor and sensory testing was normal. Occasional fasciculation was seen across the shoulders, in the upper arms, and around the mouth.

Investigations included complete blood count and sedimentation rate, plasma protein estimation, and serum electrolytes, all of which were normal. His creatine phosphokinase was 215 units, 375 units and 280 units on three 
separate days (N - 80 units). Lactic dehydrogenase and transaminase (S.G.O.T.) were normal.

Peripheral nerve conduction studies showed the median nerve sensory conduction within normal limits, and median and anterior tibial motor conduction at the lower limits of normal with abnormal terminal slowing in the median nerves.

Electromyography showed a fall out of motor unit and muscle fiber activity consistent with a lower motor neuron lesion. Many motor unit potentials were "giant", being over 5000 microvolts with either normal or prolonged durations.

A quadriceps muscle biopsy revealed normal nerve fibers and a histological picture consistent with neurogenic atrophy.

A chromosome analysis revealed a normal male chromosome complement (46 XY).

Dermatoglyphic analysis of the palms revealed bilaterally distally displaced maximal axial triradii (central): the observed combined maximal atd angles for the right and left palms in the patient were 138 degrees: the comparable value for age and sex in the control population being 85 degrees (S.D. 15.3).

\section{Mr. T. S. No. II - F - Y.O.B. 1939.}

This patient was first seen in October 1970 . He had noticed gradually progressive weakness of his legs for four years. This bothered him most in walking upstairs. He had a few vague pains in his shoulders and arms and knees without joint swelling. The pain seemed to be mainly in the joints rather than the muscles. There had been no cramps or jerking of his legs and no bladder symptoms. He had no difficulty swallowing and no symptoms referable to his cranial nerves.

On examination the optic discs were normal. There were no carotid or intracranial bruits. There was a facial tic on the left and a suggestion of slight left facial weakness. In addition there seemed to be some fasciculations of the face and also a few fasciculations of the tongue. There were fasciculations in the scapular region. He walked with a waddle. There was diffuse weakness of all muscle groups in the limbs. This was greatest in the quadriceps, hamstrings, and glutei and also the trunk muscles. There was marked weakness in the right deltoid and to a lesser degree the left. The reflexes were absent in the upper limbs. The knee reflexes were absent. The ankle reflexes were normal. The plantar responses were flexor. There was no sensory abnormality. The blood pressure and heart were normal.
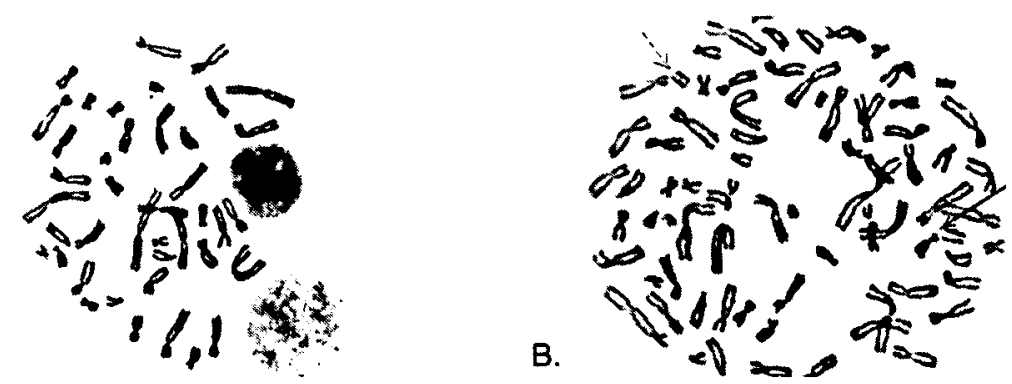

C.

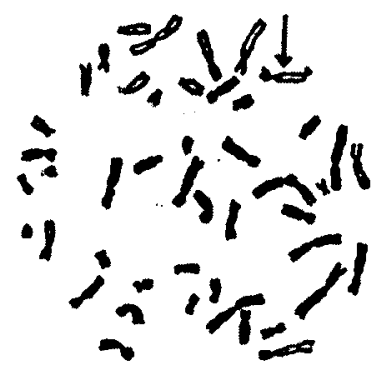

D.

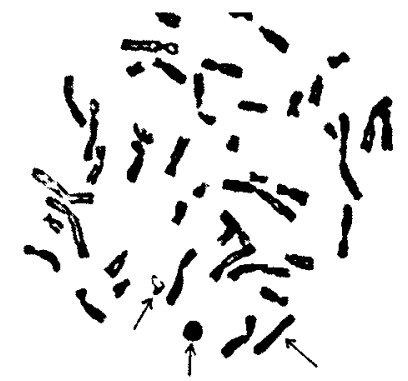

Figure 2 - Four cells with various chromosomal abnormalities representative of the high frequency of aberrations found in the patient T.S., II-F. (a) Hypodiploid cell: Total 41 chromosomes: 41 , A-, B-, 2C, G-. (b) Hypotetraploid: Total $=77$ chromosomes. Note isochromatid breakages. (c) Pseudodiploid cell; note dicentric: 46, XY, B-, Dic + . (d) Unstable pseudodiploid cell. Note ring and acentric fragments: 46, XY, 2ace. $t$, ring $t$.

Investigations: Cervical spine - normal. Lumbar spine - some flattening of the lordosis but otherwise normal. S.G.O.T. - 29 BB units. S.G.P.T. - 14 BB units. L.D.H.-290 BB units. Hemoglobin 15.4 grams percent. Hematocrit $45 \%$. WBC 9,100 . Neutrophils $72 \%$. Lymphocytes $20 \%$. Monocytes $7 \%$. Eosinophils $1 \%$. Sedimentation rate 3 millimeters per hour. Serum creatine phosphokinase 281 $\mathrm{mu}$. per ml. Aldolase $12.5 \mathrm{mu}$. per $\mathrm{ml}$.

Electromyography showed increased insertion activity in the deltoid, infraspinatus, biceps, first dorsal interosseus, quadriceps, and tibialis anterior. All of these muscles also showed fibrillation and positive waves and there were fasciculations in infraspinatus and first dorsal interosseus. The general appearance of the motor units was normal, though there was marked reduction in the number of motor units firing on voluntary contraction. Motor nerve conduction velocities were normal in the left peroneal and median nerve, though there was borderline latency at the wrist in the left median (4.5 milliseconds). Muscle biopsy of the left deltoid was normal. The left quadriceps showed no evidence of degeneration or necrosis. At one edge of the biopsy material in the transverse section, a fairly large group of severely atrophic muscle fibers was seen. Here, the fibers were reduced to small round structures with irregular nuclei and homogeneous eosinophilic cytoplasm. There was no evidence of inflammation or degeneration.

\section{CHROMOSOME ANALYSIS}

The first chromosome analysis (peripheral blood - 72 hour leukocyte culture) was done in January, 1971, six years after onset of symptoms of neurogenic SMA. The conventional methods of culturing and harvesting (modification of Moorhead et al, 1960) were employed. A total of 40 metaphase plates were analysed in detail microscopically and from photomicrographs, and a few complete karyotypes were prepared. The results showed a modal chromosome number of 46 chromosomes per cell and a normal male karyotype: 46, XY. However, a high frequency of cells ( 9 out of the 40 cells: $22.5 \%$ ) with various chromosomal abnormalities were observed. These included cells with aneuploidy (hypodiploidy, hyperdiploidy, and pseudodiploidy ranging in total number from 43 to 47 chromosomes) and mitotically unstable cells with acentric fragments (ranging in size from $G$ to a $C$ group), a ring, a dicentric, and cells with structurally altered chromosomes. This finding of a significantly increased frequency of chromosomally abnormal cells has not been described previously in connection with spinal muscular atrophy. It is known, however, that similar nonspecific chromosomal alterations occur 
spontaneously in multiple tissues in patients with Bloom's syndrome, Fanconi's anemia and ataxia telangiectasis (Hecht et al, 1966). All three of these disorders have in common recessive genetic etiology, intrauterine growth retardation, short stature, no immunologic deficiency, and an increased risk of malignancy (Bloom, 1970).

Since it is known that chromosomal aberrations can occur as a result of exogenous factors such as radiation, viral infections or drugs, it was decided to repeat the analysis in November, 1972 approximately two years later. Analysis of a total of $\mathbf{4 0}$ metaphase plates similarly revealed a persistently high frequency (20\%: 8 out of 40 cells) of cells with gross aberrations including hypodiploidy (6 cells), hypotetraploidy (1 cell with 77 chromosomes and 2 isochromatid breakages), cells with dicentrics ( 2 cells), and structural chromosomal alterations (a giant acrocentric; a B deficient for 2/3's of the short arms).

The observed frequencies on both occasions of 20 and $22.5 \%$ are compared to a mean overall proportion of aneuploidy of 2-6\% for both sexes at all ages.

It is postulated that a metabolic factor specific to this spinal muscular atrophy may be operative as an inducive factor to the chromosomal aberrations observed in the patient. However, no similar aberrations of the chromosomes were found on analyzing the patient's brother, R.S. (II E) who is similarly affected with SMA (Hamerton, 1972).

\section{DERMATOGLYPHIC ANALYSIS} (PALMS): (T.S. II.F.)

1. Excess of digital whorl patterns ( 9 out of 10.)

II. A simian crease (a single transverse palmar crease) is present across the right palm unilaterally: such is present in $2 \%$ of the control population.

III. Bilaterally, distally located central axial triradii are present; the combined maximal angles for the right and left palms in the patient is 144 degrees: the mean comparable value for age and sex in the control population being 85 degrees (S.D. $=15.3$ ) (Holt, 1968).

IV. A 'Whorl/Loop' pattern complex is present bilaterally in the Thenar/ Interdigital area of the palm (as in $2 \%$ of the control population).

Impression: these are unusual dermatoglyphics. It is possible dermatoglyphic findings may be of diagnostic value prior to onset of SMA. In this family similar unusual findings were present in both
SMA affected brothers, but not in the healthy brother. (P.S. No. II-A). The other healthy brother (W.S. No. II-H) displayed a simian crease on both hands. Dermatoglyphic analysis were not done on this person.

Mrs. D. T. No. II - G - Y.O.B. 1941.

Examination was done courtesy of Dr. J. David Grimes, Ottawa. She had no complaints and no signs of neuromuscular disease. Serum enzymes, including L.D.H., S.G.O.T. and C.P.K. were normal.

Mr. W. S. No. II - H - Y.O.B. 1942.

This patient had no symptoms and no evidence of disease of muscles or the nervous system. No fasciculations were evident. He had a simian crease on both hands. Serum enzymes were all normal. Chromosome studies showed a normal male karyotype (46 XY).

Mrs. E. W. No. II - J - Y.O.B. 1944.

No complaints and a normal neurological examination; S.G.O.T., L.D.H. and C.P.K. all normal. Chromosome analysis revealed a normal female karyotype (46XX) with no apparent abnormalities.

The first born male child in generation II died at approximately one year of age. This was said to be due to a spinal disorder. No autopsy record could be found.

\section{DISCUSSION}

\section{Inheritance:}

The basic question in the classification and genetics of spinal muscular atrophy (Research Group on Neuromuscular Diseases, 1968; Zellweger et al, 1969; Winsor et al, 1971 ) is whether it is a single genetic disease entity with widely variable phenotypic expression or whether it is several genetic disease entities caused by heterogeneous mutant genes at different loci and with possibly variable modes of genetic transmission.

In SMA there is a wide range in age of onset, progression, clinical manifestations, and life span. In contrast to this wide range of interfamilial variability, a relatively narrow range of intrafamilial variability was generally observed (Zellweger, 1969). Pedigree analysis of various families with SMA has shown different modes of genetic transmission including autosomal recessive, autosomal dominant with variable penetrance, and X-linked recessive. In McKusick's Mendelian Inheritance in Man (1971) several well recognized categories are listed. Childhood muscular atrophy includes two main forms; severe, rapidly progressive infantile (Werdnig-Hoffmann) and the more benign juvenile (KugelbergWelander) form. These are distinguishable mainly by the age of onset ranging from congenital to two years of age in the infantile, and from two years to 17 years of age in the juvenile. Both of these forms of childhood SMA are inherited as autosomal recessive. Because of the observations made in one sibship of both early and late onset, Winsor et al (1971) support the concept of one gene theory (not necessarily allelic) for childhood muscular atrophy, i.e. most familial cases of SMA being caused by an autosomal recessive gene at one locus. In amyotrophic lateral sclerosis, both autosomal dominant (irregular) and autosomal recessive variants have been reported. For proximal spinal and bulbar muscular atrophy there is evidence (Kennedy et al, 1968) for $\mathrm{X}$-linked recessive inheritance.

In the family reported here, although the pedigree (Figure I) is classical for X-linked recessive inheritance, with the age of onset being in the mid-late twenties, autosomal recessive inheritance remains a distinct possibility. In generation II, the first-born male died at 1 year of age. The cause of death could not be certified, but was reportedly due to a spinal disorder. Of the four surviving males in generation II, two are similarly affected with SMA, but none of the five females in the same sibship is affected. So far none of the members of generation III has shown any signs of SMA - this would be expected according to the later age of onset. If the X-linked theory is tentatively favored, only two males (sons of $D$ and $J$, generation II) out of the existing five males in generation III would have a high risk ( 1 in 4 ) of developing SMA at mid-late twenties. The 'original' presumptive heterozygous carrier of this X-linked recessive gene for SMA is probably the female in generation I. By following these high risk members of generation III one may ultimately provide 
a definite answer as to the $\mathrm{X}$-linked recessive versus the autosomal recessive nature of genetic transmission in the family.

The clinical manifestations of the two affected males presented here appear to fit well with the X-linked muscular atrophy reported by Kennedy et al (1968) with two major exceptions: (1) Apart from the facial fasciculations in the present patients there are no significant bulbar signs, and specifically there is no dysphagia. This is contrasted with the characteristic bulbar palsy including tongue fasciculations and atrophy, dysphagia and dysarthria in the patients reported by Kennedy. (2) The age of onset in the present patients is 10-15 years earlier than the average age of onset reported by Kennedy. On the other hand, the remaining symptoms are in relatively good agreement between the two groups. For example: the disease is either stationary or slowly progressive over a 10 year period and is compatible with a long life-span. Gynecomastia was present in 1 out of 2 of our patients, and 3 out of 9 of Kennedy's patients.

\section{Genetic Studies}

Because of the hereditary nature of the disease in this family, genetic studies were carried out. Chromosomal analysis in the elder brother was normal. The younger brother showed a combination of non-specific dermatoglyphic abnormalities which were unusual.

Nine out of ten of the fingertip patterns were whorls, a Simian crease was present in the right palm, and a distal axial triradius bilaterally and a whorl/loop pattern in the thenar interdigital area of the left palm only were present. In addition, chromosome analysis showed $30 \%$ of cells with non-specific and multiple aneuploidy. (Fig. 2). Repeat studies two years later have shown a similar percentage of abnormal cells. The basic karyotype, however, is a normal male $46 \mathrm{XY}$. Of the unaffected siblings, three had chromosomal analyses which were normal and one had dermatoglyphics which were also normal. One had a bilateral Simian palm crease.

The pedigree in this family suggests an autosomal recessive inheritance, or possibly X-linked. There is some recent literature suggesting that the late onset variant of WohlfartKugelberg-Welander Syndrome may be X-linked. It is also interesting to speculate whether the child who died at one year from a "spinal disorder" suffered from Werdnig-Hoffmann's disease since there is also a suggestion that the hereditary spinal atrophies may be a spectrum of disease from Werdnig-Hoffmann's syndrome to adult motor neuron disease.

The presence of a high percentage of non-specific abnormalities in cells on chromosomal analysis is unusual and we cannot find other reports of similar findings in this syndrome. Similar findings, however, have been found in the Louis-Bar syndrome and Fanconi's anemia.

Some of the relevant literature is reviewed. The difficulties of early diagnosis are discussed, as the presentation is like a myopathy rather than neurogenic disease. All ancilliary aids such as muscle biopsy, EMG, conduction studies, and muscle enzyme studies are important. The elevated muscle enzymes may be misleading and may be found in chronic neurogenic disease, sometimes associated with mixed neuropathic/myopathic changes on biopsy.

The relatively benign course of this form of spinal muscular atrophy, with occasional periods of improvement, is noted. The younger brother has apparently improved slightly.

Chromosomal studies and dermatoglyphics would seem to be indicated in further examples of this disease.

\section{ACKNOWLEDGEMENTS}

Gratefully acknowledged are the genetic investigations contributed towards this publication by the Department of Genetics, The Children's Hospital of Winnipeg; Dr. John L. Hamerton, Director, (chromosome analysis on 3 members), and Dr. G. C. Ducasse (dermatoglyphic analysis on 1 affected member). Mr. F. Bauder, B.Sc., carried out the analysis.

We are also grateful to Dr. Peter Siemens of Saskatoon for examing one of the patients and
Dr. David Grimes of Ottawa for examing two others.

\section{REFERENCES}

ALMOG, C., TAL, E. (1968). A family with Kugelberg Welander syndrome. Hereditary proximal spinal muscular atrophy - some additional features. Confina Neurologica 30: 313-24.

AMICK, L. D., SMITH, H. L., JOHNSON, W. W. (1966). An unusual spectrum of progressive spinal muscular atrophy. Acta Neurologica Scandánavia 42: 275-95.

ARMSTRONG, R. M., FOGELSON, M. H., SILBERBERG, D. H. (1965). Familial proximal spinal muscular atrophy. Study of a large pedigree. Transactions of the American Neurological Association. 90: 207-10.

ARMSTRONG, R. M., FOGELSON, M. H., and SILBERBERG, D. H. (1966). Familial proximal spinal muscular atrophy. Archives of Neurology 14: 208-212.

BLOOM, A. D. (1972) Induced Chromosomal Aberrations in Man: Advances in Human Genetics by H. Harris and K. Hirschhorn, Plenum Press. New York-London.

BUCHTAL, F., OLSEN, P. Z. (1970). Electromyography and muscle biopsy in infantile spinal muscular atrophy. Brain 93: 15-24.

ENGEL, K. W., HOGENHUIS, L. (1965). Discussion of paper by Armstrong et al. Transactions of the American Neurological Association.

ESPINOSA, R. E., OKIHIRO, M. M., MULDER D. W., SAYRE, G. P. (1962). Hereditary amyotrophic lateral sclerosis. Neurology (Minneap.) 12: 1-7.

FARMER, T. W., ALLEN J. N. (1969). Hereditary proximal amyotrophic lateral sclerosis. Transactions of the American Neurological Association 94: 140-4.

FENICHEL, G. M., EMERY, E. W., HUNT, P. (1967). Neurogenic atrophy simulating facioscapular humeral dystrophy; a dominant form. Archives of Neurology (Chicago) 17: 257-60.

FLECK, H., ZURROW, H. B. (1967). Familial amyotrophic lateral sclerosis. New York Journal of Medicine 67: 2368-73.

GARDNER, J. H., FELDMAHN, A. (1966). Hereditary adult motor neurone disease. Report of 154 year geneology with eighteen cases. Transactions of the American Neurological Association. 91: 239-41.

GARDNER-MEDWIN, D., WALTON, J. N. (1967). Benign spinal muscular atrophy arising in childhood and adolescence. Journal of Neurological Science. 5: 121-58.

GARG, B. K., SRIVASTAVA, J. R. (1968). Familial juvenile amyotrophic lateral sclerosis. Indian Pediatrics 5: 119-21.

GARVIE, J. M., WOOLF, A. L. (1966). Kugelberg Welander Syndrome. British Medical Journal 5501: 1458-61.

GOTO, I., PETERS, H. A., REESE, H. H. (1967). Creatine phosphokinase in neuromuscular disease. Patients and families. 
Archives of Neurology (Chicago) 16: 529-35.

GREEN J. B. (1960). Familial amyotrophic lateral sclerosis occurring in four generations. Neurology (Minneap.). 10: $960-2$.

GROSS, M., (1966). Proximal spinal muscular atrophy, Journal of Neurology, Neurosurgery, and Psychiatry 29: 29-34.

HECHT, F., KILER, R. D., RIGAS, D. A., DAHNKE, G. S., CASE, M. P., TISDALE, V. and MILLER, R. W. (1966). Leukemia and lymphocytes in ataxia telangiectasia, Lancet 2; 1193.

HIRANO, A., KURLAND, L. T., SAYRE, G. P. (1967). Familial amyotrophic lateral sclerosis. A subgroup characterized by posterior and spino-cerebellar tract involvement and hyaline inclusions in the anterior horn cells. Archives of Neurology (Chicago). 16: 232-43.

HOLT, S. B. (1968). The Genetics of Dermal Ridges, Charles C, Thomas, Publisher.

KENNEDY, W. R., ALTER, M., SUNG, J. H. (1968). Progressive proximal spinal and bulbar muscular at rophy of late onset. A sex linked recessive trait. Neurology (Minneap.) 18: 671-80.

KUGELBERG, E., WELANDER, L. (1952). Familial neurogenic (Spinal) muscular atrophy simulating ordinary proximal dystrophy. Twelfth Congress of Scandinavian Neurologists, Oslo.

KUGELBERG, E., WELANDER, L. (1956). Heredofamilial proximal spinal muscular atrophy simulating muscular dystrophy. Archives of Neurology and Psychiatry (Chicago). 75: 500-509.

KURLAND, L. T., MULDER, D. W. (1955). Epidemiologic investigations of amyotrophic lateral sclerosis. Familial aggregations indicative of dominant inheritance. Part I. Neurology (Minneap.) 5 (3) 182-196.

KURLAND, L. T., and MULDER, D. W. (1955). Epidemiologic investigations of amyotrophic lateral sclerosis. Familial aggregations indicative of dominant inheritance. Part II. Neurology (Minneap.) 5 (4) 249-268.

KURLAND, L. T. (1957), Epidemiologic investigations of amyotrophic lateral sclerosis. III. A genetic interpretation of incidence and geographic distribution. Proceedings of the Mayo Clinic 32: (17), 449-62.

MAGEE, K. R., DEJONG, R. N. (1960), Neurogenic muscular atrophy simulating muscular dystrophy. Archives of Neurology (Chicago) 2: 677-82.

MASTAGLIA, F. L., WALTON, J. N. (1971). Histological and histochemical changes in skeletal muscle from cases of chronic juvenile and early adult spinal muscular atrophy. (The Kugelberg Welander Syndrome). Journal of Neurological Science 12: $15-44$.

MEADOWS, J. C., MARSDEN, C. D., HARRIMAN, D. G. (1969). Chronic spinal muscular atrophy in adults. 1. The
Kugelberg-Welander syndrome. Journal of Neurological Sciences 9: 527-50.

METCALF, C. W., HIRANO, A. (1971). Amyotrophic lateral sclerosis. Clinicopathological studies of a family. Archives of Neurology 24: 518-23.

McKUSICK, VICTOR A., Mendelian Inheritance in Man; Catalogs of Autosomal Recessive and X-linked Phenotypes: 3rd Edition, Baltimore, The John Hopkins Press, (1971).

McLEOD, J. G., WILLIAMS, I. (1971). Spinal muscular atrophy. Minnesota Medicine 54: 475-61.

MOOREHEAD, P. S., NOWELL, P. C., WELLMAN, W. J., BATTIPS, D. M. AND HUNGERFORD, D. A. (1960). Chromosome preparations of leucocutes cultured from human peripheral blood. Experimental Cell Research 20,613.

PANITCH, H. S., FRANKLIN, G. M. (1972). Elevation of serum creatine phosphokinase in amyotrophic lateral sclerosis. Neurology 22: $964-966$

PEARCE, J., HARRIMAN, D. G. (1966). Chronic spinal muscular atrophy. Journal of Neurology, Neurosurgery \& Psychiatry 29: 509-20.

PERRY, I.S., NETSKY, M. G. (1958). Familial amyotrophic lateral sclerosis-report of two cases. North Carolina Medical Journal 19: (6) 229-34.

POSER, C. M., JOHNSON, M., BUNCH, L. D. (1965). Familial amyotrophic lateral sclerosis. Diseases of the Nervous System 26: 697-702.

POWER, J. M., HOROUPIAN, D. S., SCHAUMBERG, H. H. (1974) Wetherbee Ail. Canadian Journal of Neurological Sciences 1: 139-140.

PRATT, R. T. C. (1962). Genetic aspects of motor neurone disease. Proceedings of the Royal Society of Medicine 55: 1020-1.

QUARFORDT, S. H., DeVIVO, D. C. ENGEL, W. K., LEVY, R. I., and FREDRICKSON, D. S. (1970). Familial AdultOnset Proximal Spinal Muscular Atrophy. Archives of Neurology 22: 541-549.

RESEARCH GROUP ON NEUROMUSCULAR DISEASES (1968) - Classification of the Neuromuscular Disorders. Journal of the Neurological Sciences 6: 165-177.

ROE, P. F. (1964). Familial motor neurone disease. Journal of Neurology, Neurology, Neurosurgery \& Psychiatry. 27: 140-3.

ROTH, R. G., GRAZIANI, L. J., TERRY, R. D., SCHEINBERG, L. D. (1965). Muscle fine structure in the Kugelberg Welander syndrome (chronic spinal muscular at rophy). Journal of Neuropathology and Experimental Neurology 24: 444-54.

SERCL, M., KOVARIK, J. (1963). On the familial incidence of amyotrophic lateral sclerosis. Acta Neurologica Scandinavia 39: 169-76.

SMITH, J. B., PATEL, A. (1965). The Wohlfart Kugelberg Welander disease. Review of the literature and report of a case. Neurology (Minneap.) 15: 469-473.

SPIRA, R. (1966). A family with Kugelberg Welander disease, electromyographic findings in sub-clinical cases. Confina Neurologica 28: 423-31.

TAKAHASHI, K., NAKAMURA, H., OKADA, E. (1972). Hereditary Amyotrophic Lateral sclerosis. Archives of Neurology 27: 292-299.

THOMSON, A. F., ALVAREZ, F. A. (1969). Hereditary amyotrophic lateral sclerosis. Journal of Neurological Sciences 8: 101-10.

TORRES, J., IRIARTE, L. L. (1957). Amyotrophic lateral sclerosis among Guamanians in California. California Medicine 86: (6) 385-8.

TSUKAGOSHI, H., NAKANISKI, T., KONDO, K. (1965). Hereditary proximal neurogenic muscular atrophy in adult. Archives of Neurology (Chicago). 12: 597-603.

TSUKAGOSHI, H., SUGITA, H., FURUKAWA, T. (1966). Kugelberg Welander syndrome with dominant inheritance. Archives of Neurology (Chicago). 14: 378-81.

TSUKAGOSHI, H., SHOJI, H., FURUKAWA, T. (1970). Proximal neurogenic muscular atrophy in adolescence and adulthood with $\mathrm{x}$-linked recessive inheritance. Neurology 20: 1188-1193.

WELANDER, L. (1955) quoted by Wohlfart, G., Fex, J., Eliasson, S.

WELCH, K. M. A., GOLDBERG, D. M. (1972). Serum creatine Phosphokinase in Motor Neuron Disease. Neurology 22: 697-701.

WINSOR, E. J., MURPHY, E. G., THOMP. SON, M. W. AND REED, T. E. (1971). Genetics of childhood spinal muscular atrophy. Journal of Medical Genetics, 8:143-148.

WOHLFART, G. (1942). Zwei falle von dystrophia musculorum progressiva mit fibrallaren zuckussgen und atypischen muskelbefund. Deutsche Zeitschrift fur Neruenheilkunde 153: 189-93.

WOHLFART, G., FEX, J., ELIASSON, S. (1955). Hereditary proximal spinal muscular atrophy - a clinical entity simulating muscular dystrophy. Acta Psychiatrica Scandinavia 30: 395-406.

WOODS, B. T., SCHAUMBERG, H. H. (1972). Nigro-spino-dentatal degeneration with nuclear ophthalmoplegia. Journal of Neurological Sciences 17: 149-166.

ZELLWEGER, H., SCHNEIDER, H., SCHULDT, D. R. (1969). A new genetic variant of spinal muscular atrophy. Neurology. (Minneap.) 19: 865-9.

ZELLWEGER, H., SIMPSON, J., McCORMICK, W. F., IONASESCU, V. (1972). Spinal muscular atrophy with autosomal dominant inheritance. Neurology 22: $957-963$ 